\title{
Ingrowing Nail Correction by Advancing Composite Flap of the Nailbed and Periosteum-A Simple and Effective Technique
}

\author{
Adil Mohammed Hashish, Medhat Emil Habib, Said Al-Busaidi \\ Department of Plastic, Reconstructive and Craniofacial Surgery, Khoula Hospital, Muscat, Sultanate of Oman \\ Email: adelhashish@hotmail.com
}

Received 8 February 2014; revised 5 March 2014; accepted 13 March 2014

Copyright (C) 2014 by authors and Scientific Research Publishing Inc.

This work is licensed under the Creative Commons Attribution International License (CC BY). http://creativecommons.org/licenses/by/4.0/

\begin{abstract}
Ingrowing toenails are common particularly in young adults. They usually result in a prolonged period of discomfort or pain that is sufficient to interfere with working and social activities. Apart from the toes, ingrowing nails can affect the fingers as well. Surgery is still the mainstay of treatment. A number of techniques have been described in the literature. But in all there is a high recurrence rate and sometimes the cosmetic result is not acceptable. In this article we describe our technique of surgical management of ingrowing nails of the toes and fingers. The technique involves excision of a part of the lateral nail fold and raising a composite flap consisting of the nail bed and the underlying periosteum which is then advanced. 105 cases were operated using this technique with very good postoperative results.
\end{abstract}

Keywords

Ingrowing; Toenail; Fingernail; Composite Flap; Nailbed

\section{Introduction}

The ingrowing nail generally occurs in the great toes, but other toes can be affected. Fingernails can also have the same disorder after trauma but this is a rare condition.

The treatment options of ingrowing nails include either conservative or surgical treatment based on the stage of the disease. Surgery is still the mainstay of treatment [1]-[3]. A number of surgical procedures have been described including simple nail avulsion, wedge excision, phenolisation and Zadik procedure with complete ex- 
cision of nail bed [4] [5].

In spite of the availability of a wide number of surgical procedures for correction of ingrowing toe nail, there is still a high recurrence rate. In addition, the cosmetic results in some of these procedures are poor and sometimes the healing time is prolonged. Our technique is very simple and the procedure is easy to perform. We believe that it gives good results in term of short healing time, low recurrence rate, acceptable cosmetic results and high patient satisfaction.

\section{Patients and Methods}

Between July 2000 and December 2010, 105 cases of ingrowing nails were corrected by advancing composite flap of the nail bed and the periosteum. The procedure was done after getting a written consent from the patients. All of the cases were done by the same surgeon (first author). Follow up period of the cases ranged from 6 months to 8 years. Approval of Khoula hospital ethical committee was obtained for publication of this study.

\section{Surgical Technique (Figure 1)}

The procedure is carried out under digital block anesthesia (using $2 \%$ xylocaine without adrenaline) and using a glove tourniquet. Initially the intended site of incision is marked and the incision is carried out. The first step is excision of part of the lateral nail fold and the corner where the lateral nail fold meets the proximal nail fold. This is the area where the nail plate is ingrowing and is embedded in the soft tissues. Subsequently blunt dissection is used to separate the vertically ingrowing nail plate from the underlying nail bed to avoid nail bed trauma. Excision of the granulation tissue is then carried out leaving healthy lateral skin edge. Small part of the nail plate at the edge and the ingrowth is then excised. Any excess granulation tissue is removed to leave a healthy bed. Haemostasis is then secured. Using a scalpel a composite flap consisting of the nail bed and the underlying periosteum is then raised. The flap is dissected, elevated and advanced over the defect. The flap is then sutured to the lateral healthy skin edge using absorbable 5/0 Vicryl or non absorbable Nylon sutures (need to be removed). The repair is covered by a paraffin gauze dressing and light bandage. The $1^{\text {st }}$ dressing is done after 2 to 3 days. The same technique is used for the fingers (Figure 2).

\section{Results}

105 cases were included in the study with age range of 12 to 40 years. 11 cases were previously operated using other surgical procedures in other units and presented to us with recurrence. One of the cases presented with recurrence for the third time and two cases with a recurrence for the second time (Table 1). 9 cases had both big toes involved. 3 of them were operated at the same surgical session and 6 were operated at separate sessions. 10 patients presented with excessive granulation tissue and pyogenic granuloma formation.

The usual presentation was ingrowing nail of the great toe. Other toes were involved in 2 cases. With regards to the fingers there were 3 cases with involvement of the thumb, 2 cases in which the middle finger was in-

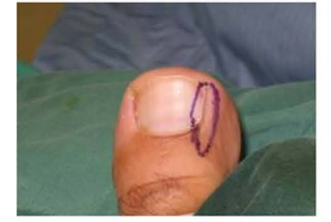

A. Marking for the part to be excised

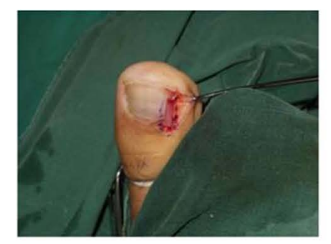

E. Exposure of nailbed

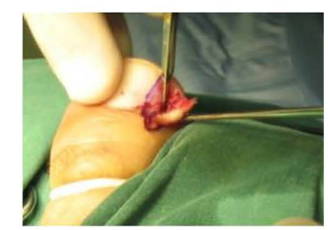

B. Nailfold excision

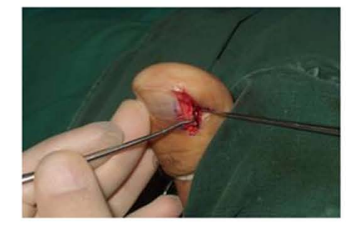

F. Elevation of composite flap

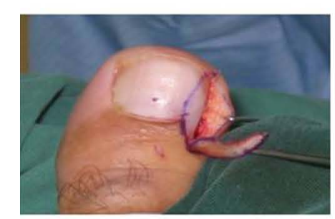

C. Nail fold excision

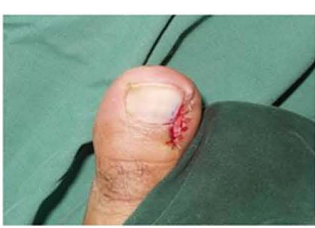

G. Flap advancement and closure

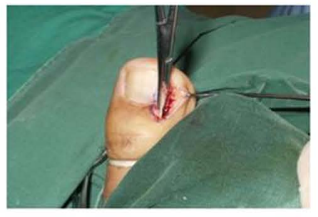

D. Excision of nail plate

Figure 1. Surgical technique. 


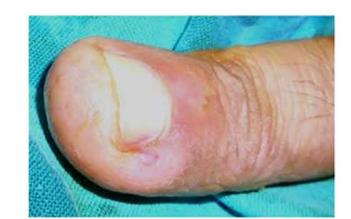

A. Ingrowing nail on the middle finger

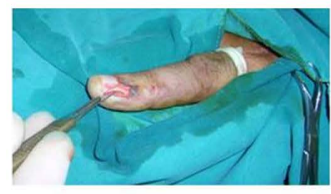

E. Raising the composite flap

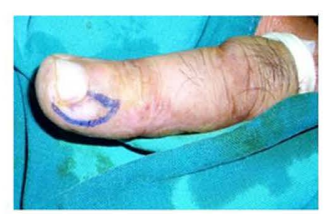

B. Planning the incision for nail fold excision

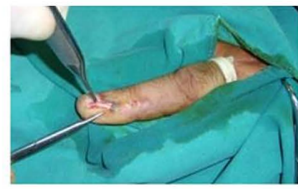

F. Advancing the flap over the skin edge

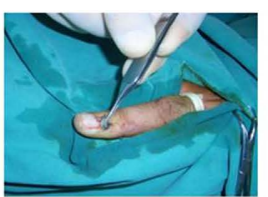

C. Nail fold excision

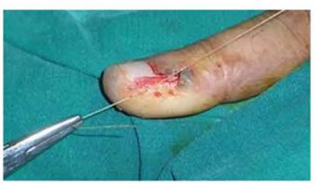

G. Wound closure

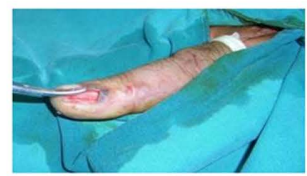

D. Excision of nail plate

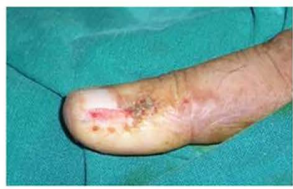

H. After closure is complete

Figure 2. Surgical technique on the fingers.

Table 1. Presentation.

\begin{tabular}{ccc}
\hline Presentation & Number & Percentage \\
\hline Primary & 94 & $89.52 \%$ \\
Recurrent & 11 & $10.48 \%$ \\
Unilateral & 96 & $91.43 \%$ \\
Bilateral & 9 & $8.57 \%$ \\
Total & 105 & $100 \%$ \\
\hline * One case with $3^{\text {rd }}$ recurrence. Two cases with $2^{\text {nd }}$ recurrence.
\end{tabular}

volved, 2 cases the ring finger was involved, and one case involving the index finger (Table 2).

The most common causes were related to poor habits of cutting the nails, improper fitting shoes, trauma, preexisting deformity and anomaly of the foot. The main presenting symptoms and signs were persistent pain, chronic discharge, recurrent infection, and excessive granulation tissue formation.

Healing time was usually between one to two weeks. One case operated after the $3^{\text {rd }}$ recurrence had infection and the wound took longer time to heal. All the patients were satisfied and happy with the results.

The cases with the usual presentation of great toe involvement had a follow up period from 6 months to one year. During this period no recurrence was noticed in these cases. The 9 cases of bilateral great toes involvement had a follow up period of 2 years and there was no recurrence in any of these cases.

10 patients had a follow up for 8 years. These were the cases of unusual presentation, difficult cases, cases with involvement of both sides of the same big toe and cases with pre-existing foot anomaly. None of these patients had a recurrence.

Although all the patients were satisfied, we noticed that the cosmetic results of operated big toe were superior to that of the fingers and this may be related to the relative difference of thickness of the nail bed in both. Examples of post operative results are shown in (Figures 3-6).

\section{Discussion}

The exact aetiology of ingrowing toenails (IGTNs) is not fully understood. Several aetiological factors have been implicated, including tight-fitting shoes, trauma, incorrect trimming of toenails, poor foot hygiene, hyperhydrosis, malalignment of the matrix, abnormally long toes, congenital excessive convexity of the nails, and prominence of the nail folds [4]-[13].

A recent study by Kosaka et al. found no statistical difference on the basis of morphologic parameters between the normal and ingrown nail [14].

The disease process of IGTNs consists of three stages [4] [5] [9] [10]. Each stage has certain features:

1) Stage one: Inflammation, swelling, and pain. 
Table 2. Site of the ingrowing nail.

\begin{tabular}{cc}
\hline Site & Number \\
\hline Big toe & 95 \\
Other toes & 2 \\
Thumb & 3 \\
Index finger & 1 \\
Middle finger & 2 \\
Ring finger & 2 \\
Total & $\mathbf{1 0 5}$ \\
\hline
\end{tabular}

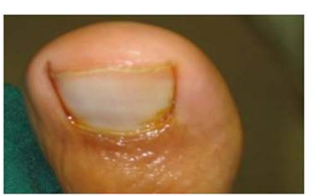

A. Left big toe of the patient in figure 1

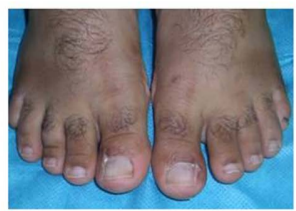

One month post op

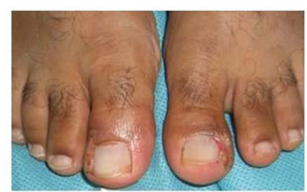

B. One week post operative of both big toes

Figure 3. Post operative result.

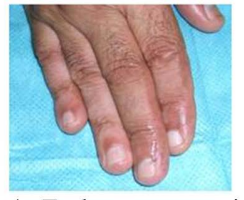

A. Early post operative of the patient in figure 2

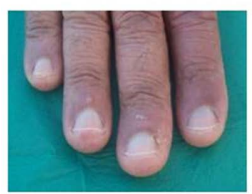

C. Six years post operative

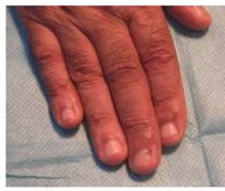

B. Few months post operative

Figure 4. Post operative result.

2) Stage two: Inflammation, pain, non healing wound with oozing, and granulation tissue formation.

3) Stage three: Abscess formation and chronic induration of the lateral nail fold [9].

The exact incidence of the ingrowing toe nail in the general population is not known, but Wallace et al. (1979) estimated an approximate annual incidence of 1 per 1000 of the population in the Newcastle area of England [7].

Approximately two thirds of patients who are affected are males [15] [16]. The condition predominantly affects young people who are often in their second or third decades of life [5] [8] [12]. 85\% of cases occurring in people aged between 9 and 29 years [17]. The condition is painful and may lead to time off work or school in addition to restricting recreational activities.

Conservative management is generally unsatisfactory, and to be successful requires careful and time-con- 


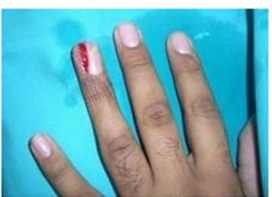

A. Preoperative left ring finger

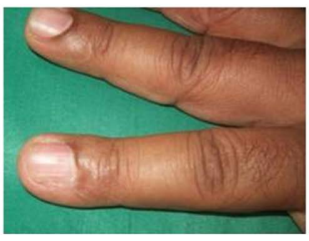

C. 6 years post operative

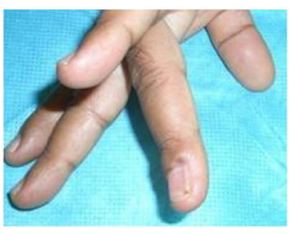

B. 4 months post operative

Figure 5. Pre and post operative results.

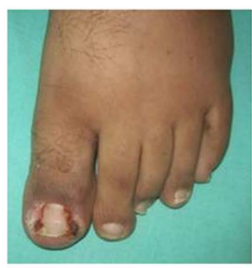

A. Pre op both sides of left big toe with predisposing congenital foot anomaly

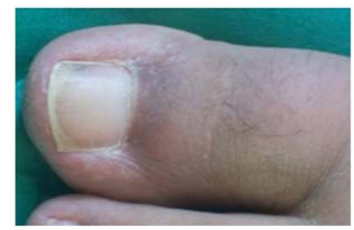

C. 2 years post op

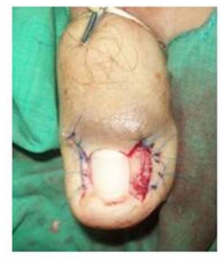

B. Immediate post op

Figure 6. Pre and postoperative results.

suming follow-up with a high degree of patient compliance [17]. A number of surgical procedures have been described, but there is still a high recurrence rate with all the procedures. Simple avulsion of the nail has an unacceptably high recurrence rate (70\% to 86\%) [15] [16]. Zadik's operation of total proximal nail bed ablation has a reported symptomatic recurrence rate between $16 \%$ and $33 \%$ [18].

Our technique is simple. It does not involve excision of the nail bed at all.

Advancing the nailbed with the periosteum over the lateral skin edge produces a flat nail which in turn reduces the possibility for the nail to grow in again. Other procedures that involve only the excision of the nail bed have a long healing time that takes 3 to 6 weeks. There is often a higher recurrence rate and poorer cosmetic results. The nail becomes dystrophic, particularly when the operation involves nail avulsion. The nail usually grows markedly narrow, distorted, onycholytic, thickened, discolored, and deviated [9].

Our procedure involves excision of part of the skin. Vandenbos technique involves also skin excision but this is done without alteration of the nailbed [19]. The disadvantage of that technique is the long healing time [9].

The end result of the procedure we are describing is a flat nail. B. Ozdil et al. have reported a non surgical technique to make the nail flat by correcting the convexity of the nail and reducing its thickness using a nail file [5]. This procedure can only be useful in a thick convex nail.

Ingrwoing nails of the fingers are rarely reported in the literature. We report 8 cases in this study. This represents $8.4 \%$ of the total number of cases. 
The short healing time and acceptable cosmetic appearance resulted in high patients satisfaction.

\section{Conclusion}

We believe that our technique is simple and highly effective for ingrowing nails correction with low recurrence rate, good cosmetic results and high patient satisfaction.

\section{References}

[1] Bostanci, S., Ekmekci, P. and Gurgey, E. (2001) Chemical Matricectomy with Phenol for the Treatment of Ingrowing Toenail: A Review of the Literature and Follow Up of 172 Treated Patients. Acta Dermato-Venereologica, 81, 181183. http://dx.doi.org/10.1080/000155501750376267

[2] Abby, N.S., Roni, P., Amnon, B. and Yan, P. (2002) Modified Sleeve Method Treatment of Ingrowing Toenail. Dermatologic Surgery, 28, 852-855. http://dx.doi.org/10.1046/j.1524-4725.2002.02040.X

[3] Peyvandi, H., Robati, R.M., Yegane, R., Hajinasrollah, E., Toossi, P., Peyvandi, A., Ourang, Z.B. and Shams, A. (2011) Comparison of Two Surgical Methods (Winograd and Sleeve Method) in the Treatment of Ingrown Toenail. Dermatologic Surgery, 37, 331-335. http://dx.doi.org/10.1111/j.1524-4725.2011.01880.x

[4] Mitchell, S., Jackson, C.R. and Wilson-Storey, D. (2011) Surgical Treatment of Ingrown Toenails in Children: What Is Best Practice. Annals of the Royal College of Surgeons of England, 93, 99-102. http://dx.doi.org/10.1308/003588411X12851639107674

[5] Ozdil, B. and Eray, I.G. (2009) New Method Alternative to Surgery for Ingrown Nail: Angle Correction Technique. Dermatologic Surgery, 35, 990-992. http://dx.doi.org/10.1111/j.1524-4725.2009.01169.x

[6] Sonnex, T.S. and Dwber, R.P.R. (1985) Treatment of Ingrowing Toenails with Liquid Nitrogen Spray Cryotherapy. British Medical Journal, 291,173-175. http://dx.doi.org/10.1136/bmj.291.6489.173

[7] Tweedie, J.H. and Ranger, I. (1985) A Simple Procedure with Nail Preservation for Ingrowing Toe-Nails. Archives of Emergency Medicine, 2, 149-154. http://dx.doi.org/10.1136/emj.2.3.149

[8] Mansavi, S.R. and Khoshmevice, J. (2012) A New Surgical Technique for Ingrowing Toenail. International Scholarly Research Network, 1-4.

[9] Haneke, E. (2012) Controversies in the Treatment of Ingrown Nails. Dermatology Research and Practice, 1-12. http://dx.doi.org/10.1155/2012/783924

[10] Farrelly, P.J., Minford, J. and Jones, M.O. (2011) Surgical Treatment of Ingrown Toenails in Children. Annals of the Royal College of Surgeons of England, 93, 99-102. http://dx.doi.org/10.1308/003588411X572231

[11] Nazari, S. (2006) A Simple and Practical Method in Treatment of Ingrown Nails: Splinting by Flexible Tube. JEADV, 20, 1302-1306. http://dx.doi.org/10.1111/j.1468-3083.2006.01793.x

[12] Wollina, U. (2004) Modified Emmet's Operation for Ingrown Nails Using the ER:YAG Laser. Journal of Cosmetic and Laser Therapy, 6, 38-40. http://dx.doi.org/10.1080/14764170410029077

[13] Chiacchio, N.D., Belda, W., Di Chiacc, N.G., Gabriel, F.V. and de Farias, D.G. (2010) Nail Matrix Phenolization for Treatment of Ingrowing Nail: Technique Report and Recurrence Rate of 267 Surgeries. Dermatologic Surgery, 36, 534-537. http://dx.doi.org/10.1111/j.1524-4725.2010.01490.x

[14] Kosaka, M., Kusuhara, H., Mochizuki, Y., Mori, H. and Isogai, N. (2010) Morphologic Study of Normal, Ingrown, and Pincer Nails. Dermatologic Surgery, 36, 31-38. http://dx.doi.org/10.1111/j.1524-4725.2009.01361.x

[15] Palmer, B.V. and Jones, A. (1979) Ingrowing Toenails: The Results of Treatment. British Journal of Surgery, 66, 575-576. http://dx.doi.org/10.1002/bjs.1800660818

[16] Murray, W.R. and Bedi, B.S. (1975) The Surgical Management of Ingrowing Toenail. British Journal of Surgery, 62, 409-412. http://dx.doi.org/10.1002/bjs.1800620522

[17] Lloyd-Davies, R.W. and Brill, G.C. (1963) The Aetiology and Out-Patient Management of Ingrowing Toe-Nails. British Journal of Surgery, 50, 592-597. http://dx.doi.org/10.1002/bjs.18005022407

[18] Zadik, F.R. (1950) Obliteration of the Nail Bed of the Great Toe without Shortening of the Terminal Phalanx. Journal of Bone and Joint Surgery, 32-B, 66-67.

[19] Chapeskie, H. (2008) Ingrown Toenail or Overgrown Toe Skin? Alternative Treatment for Onychocryptosis. Canadian Family Physician, 54, 1561-1562. 